\title{
ANALISA SAFETY FACTOR SHEET PILE PADA PLTMG PONTIANAK PEAKER DENGAN APLIKASI GEO5
}

\author{
Muhammad Amar Sajali ${ }^{1}$, Rahmah Dara Lufira ${ }^{2}$, Suwanto Marsudi ${ }^{3}$, Aufa Hanan $\mathrm{A}^{4}$ \\ Jurusan Teknik Pengairan Universitas Brawijaya \\ e-mails: amar@ub.ac.id
}

\begin{abstract}
Abstrak Pada dekade belakangan ini, perkembangan konstruksi penahan tanah semakin berkembang pesat seiring optimalisasi penggunaan lahan yang tersedia. Tujuan dari studi ini adalah untuk menahan tanah agar tidak longsor akibat beban yang bekerja selain pemanfaatan ruang yang tersedia. Hasil analisis sheet pile pada PLTMG Pontianak Peaker didapatkan bahwa angka SF pada kondisi tanpa gempa (kondisi aman) $=2.00$ dan angka SF pada kondisi gempa $=1.40$. Berdasarkan hasil analisa sheet pile di titik S-02 dan S-03 pada kondisi-tanpa gempa, surut-tanpa gempa, banjirtanpa gempa, normal-gempa, surut-gempa, dan banjir gempa dengan gempa di kala ulang 500 tahun pada analisa struktur dan analisa stabilitas lereng dikatakan "aman" dikarenakan pada kondisi tanpa gempa nilai SF lebih besar dari 2.00 dan kondisi gempa nilai SF lebih besar dari 1.40.
\end{abstract}

Key words: Angka Keamanan, Sheet Pile, Geologi Tanah, PLTMG, GEO5

\begin{abstract}
In the past decade, the development of land retaining construction is growing rapidly as optimization of available land use. The purpose of this study is to hold the soil in order to avoid landslide due to the structural load other than the use of available space. The results of the sheet pile analysis at Pontianak Peaker PLTMG found that the SF number in the condition without earthquake (safe condition) is 2.00 and the number of SF in earthquake conditions is 1.40. Based on the results of sheet pile analysis at S-02 and S-03 points in conditions without earthquakes, low tide-without earthquakes, floods-without earthquakes, normal-earthquakes, receding earthquakes, and earthquake floods with earthquakes returning 500 years in analysis the structure and analysis of slope stability are said to be "safe" because the conditions without earthquakes SF values greater than 2.00 and earthquake conditions SF values greater than 1.40 .
\end{abstract}

Key words: Safety number, Sheet Pile, Soil Geology, PLTMG, GEO5

Turap adalah dinding vertikal relatif tipis yang berfungsi untuk menahan tanah dan untuk menahan masuknya air ke dalam lubang galian. Turap banyak digunakan pada penahan tebing galian sementara, bangunan - bangunan di pelabuhan, dinding penahan, bendungan, dan lain - lain. (Gunata, 2014) Dari segi pelaksanaan, dinding turap dapat dibedakan menjadi empat yaitu turap kantilever, dinding turap diangker, dinding turap dengan landasan (platform), bendung elak seluler (cellular cofferdam).

Menurut Das, 2011, dinding turap adalah dinding vertikal relatif tipis yang berbentuk pipih dan panjang, biasanya terbuat dari material baja atau beton yang berfungsi kecuali untuk menahan tanah juga berfungsi untuk menahan masuknya air ke dalam lubang galian. Peranan dinding turap sangat besar pada bidang teknik sipil. Dinding turap secara luas dipakai untuk struktur - struktur tepi laut atau pelabuhan baik yang besar maupun yang kecil. Untuk pelengkap fasilitas peluncuran kapal dan juga untuk dermaga -dermaga kapal. Karena pemasangan yang mudah dan biaya pelaksanaan yang relatif murah, turap banyak digunakan pada pekerjaan - pekerjaan, seperti : penahan tebing galian sementara, bangunanbangunan di pelabuhan, dinding penahan tanah, bendungan dan lain - lain.

Pada pekerjaan galian tanah, masalah utama yang dihadapi adalah adanya penggalian 
yang cukup dalam yang dapat berakibat keruntuhan (failure) tanah sekitar galian. Suatu tanah galian yang tinggi biasanya berpotensi runtuh ke arah lateral. Salah satu solusi yang dapat digunakan untuk mengatasi masalah ini adalah dengan memancang turap, dinding penahan tanah pada kedalaman tertentu. Metode ini dianggap sebagai teknik yang umum dan dapat diterima untuk penggunaan angker kadang - kadang diperlukan untuk mengurangi deformasi turap. Sistem ini dilakukan dengan cara menggali tahap demi tahap sampai kedalaman yang diperlukan.

Dalam analisis teknik, hal utama yang harus diperhatikan adalah kondisi tanah di lokasi pekerjaan. Pada umumnya kondisi tanah di alam tidak homogen, terdiri dari lapisan tanah lempung dan lapisan tanah granuler. Pada tanah granuler keruntuhan akan cepat terjadi dibandingkan dengan tanah kohesif, karena tanah granuler tidak mempunyai nilai kohesi.

Dalam suatu galian tanah, salah satu hal penting yang harus dipertimbangkan adalah adanya gerakan massa tanah di sekitar galian. Stabilitas galian dan gerakan tanah akan dipengaruhi oleh beberapa faktor, antara lain kuat geser tanah, lebar galian, jarak antara dasar galian dengan tanah keras dan kedalaman galian.

Perkembangan teknologi saat ini mengalami kemajuan yang sangat pesat, termasuk perkembangan teknologi dalam bidang geoteknik, banyak program bantu yang telah diciptakan guna memudahkan dalam perencanaan desain dan untuk mengurangi kesalahan dalam perhitungan. Salah satu program yang sering digunakan dalam bidang geoteknik adalah software Geo5, program ini merupakan program yang diciptakan untuk mempermudah proses perencanaan desain dinding penahan tanah.

Pada dekade belakangan ini, perkembangan konstruksi penahan tanah semakin berkembang pesat seiring optimalisasi penggunaan lahan yang tersedia. Tujuan dari studi ini adalah untuk menahan tanah agar tidak longsor akibat beban yang bekerja selain pemanfaatan ruang yang tersedia. Proyek pembangunan Pembangkit Listrik Tenaga Mesin Gas (PLTMG) di Pontianak Peaker 100 MW ini merupakan sebuah proyek yang pembangkit energi listrik yang menggunakan peralatan/mesin turbin gas sebagai penggerak generatornya.
PT. PLN (Persero), pembangkit PLTMG akan dibangun untuk menggantikan peran pembangkit PLTD sebagai pemasok listrik di Provinsi Kalimantan Barat. Pembangkit PLTMG yang dikembangkan adalah pembangkit yang dapat menggunakan dua jenis bahan bakar, yaitu gas bumi. Turbin gas dirancang dan dibuat dengan prinsip kerja yang sederhana dimana energi panas yang dihasilkan dari proses pembakaran bahan bakar diubah menjadi energi mekanis dan selanjutnya diubah menjadi energi listrik atau energi lainnya sesuai dengan kebutuhannya.

Sebelum melakukan pembangunan PLTMG perlu dilakukan persiapan lahan dengan cara pengurugan tanah. Dalam pengurugan tanah ini biasanya harus diperhatikan kondisi tanah di lokasi pekerjaan. Umumnya kondisi tanahnya tidak homogen, biasanya terdiri dari tanah lempung (kohesif) dan lapisan tanah granuler sehingga keruntuhan tanah granuler akan cepat terjadi dibandingan dengan tanah yang sifatnya kohesif karena tanah granuler tidak memiliki nilai kohesif . Maka dari itu perlu direncanakan pembangun sheet pile dengan mepertimbangkan adanya stabilitas ataupun keamanan sheet pile terhadap gerakan massa tanah di lokasi pengurugan.

Tujuan dari penelitian ini adalah untuk mengetahui perlunya pelaksanaan perencanaan sheet pile pada PLTMG di Pontianak Peaker 100 MW, dan mengetahui gambaran umum pelaksanaan kegiatan pemasangan sheet pile di lapangan, serta mengetahui pengerjaan perencanaan sheet pile menggunakan software Geo5.

\section{BAHAN DAN METODE}

Lokasi penelitian Situs Investigasi terletak di dalam area PLTMG Pontianak Peaker. Kordinat $0^{\circ} 3^{\prime} 37.79^{\prime \prime}$ Lintang Utara dan $109^{\circ} 12^{\prime} 14.62^{\prime \prime}$ Bujur Timur. Penyelidikan lapangan dilakukan untuk memperoleh data primer dan data sekunder. Data ini akan dianalisis untuk dipertimbangkan untuk menentukan konsep desain bangunan sheet pile. Untuk menentukan kondisi topografi di lokasi untuk menentukan tata letak yang optimal, elevasi generasi dasar, dan memotong \& mengisi volume. Berbagai survei topografi adalah sekitar 30 ha. 


\section{Investigasi Tanah}

Investigasi tanah, dilakukan di darat rencana utama pembangunan dan konstruksi pendukung lainnya, untuk menentukan desain, seperti:

a. Konfirmasi kondisi geologi, struktur terutama geologi di lapangan.

b. Interpretasi geologi dari lapisan tanah dan batuan di daerah penelitian.

c. Rekomendasi dari jenis pondasi, kapasitas menumpuk tunggal dan kedalaman (untuk setiap jenis dan tumpukan diameter), daya dukung tanah untuk pondasi dangkal, serta kapasitas dasar lain daya dukung sesuai dengan kondisi lapangan.

d. Rekomendasi untuk jenis perbaikan tanah (termasuk metode, material yang digunakan, kedalaman, waktu dan hal-hal terkait), jika ada. Penyelidikan tanah terdiri dari:
1. Cone Penetration Test (CPT)
2. Pengeboran tanah dan Standard Penetration Test (SPT)
3. Inti Sampling
4. Uji laboratorium
5. Geolistrik

\section{Pengukuran Pasang Surut}

Tidal pengukuran dilakukan untuk setidaknya 17 hari terus mengalir (terus menerus) dan harus secara simultan mengukur sungai. Elevasi di pengukuran pasang surut memiliki referensi ketinggian yang sama dengan mengacu tinggi ( $Z$ ) pada survei topografi dan barimetri. Untuk memudahkan pengikatan posisi air sungai untuk elevasi tanah, salah satu dari empat AB baru dipasang di Situs ini Investigasi Studi terletak dekat stasiun pengukuran pasang surut.

Output pengukuran pasang surut adalah karakteristik dari pasang surut air sungai di lokasi rencana tanaman. Dari karakteristik pasang surut, selanjutnya dihitung elevasi muka air yang penting, seperti MSL (pada \pm 0.00 meter), HHWL, HWL, LWL, dan LLWL.

Pada perencanaan kali ini permasalahan yang diangkat adalah merencanakan dimensi dari dinding penahan tanah dengan mengambil data SPT dan DST di daerah PLTMG Pontianak Peaker.

\section{Pengukuran Sondir}

Pengujian sondir merupakan salah satu pengujian penetrasi yang bertujuan untuk mengetahui daya dukung tanah pada setiap lapisan serta mengetahui kedalaman lapisan pendukung yaitu lapisan tanah keras. Hal ini dimaksudkan agar dalam mendesain Pondasi yang akan digunakan sebagai penyokong kolom bangunan diatasnya memiliki faktor keamanan (safety factor) yang tinggi sehingga bangunan diatasnya tetap kuat dan tidak mengalami penurunan atau settlement yang dapat membahayakan dari sisi keselamatan akan bangunan.

Pada pekerjaan penggalian tanah, masalah utama yang dihadapi adalah adanya penggalian yang cukup dalam yang dapat berakibat keruntuhan (failure) tanah sekitar galian. Suatu tanah galian yang tinggi biasanya berpotensi runtuh ke arah lateral. Salah satu solusi yang dapat digunakan untuk mengatasi masalah ini adalah dengan memancang turap, dinding penahan tanah pada kedalaman tertentu. Oleh karena itu metode untuk menghitung stabilitas sheet pile yaitu menggunakan software Geo5.

\section{Langkah kegiatan pemasangan sheet pile di Pontianak Peaker}

1. Pemancangan Corrugated Concrete Sheet Pile (Driving pile)

Alat driving pile ditentukan berdasarkan hasil uji pra-kerja pile. Meski begitu, berdasarkan hasil investigasi, alat driving bertipe vibratory hammer adalah yang disarankan. Alat driving harus dilengkapi fasilitas water jet, crawler crane dan pontoon jika perlu. Sebelum memobilisasi alat driving pile ke tempat pekerjaan, kontraktor harus menyerahkan dokumen untuk disahkan Insinyur yang berisi beberapa keterangan alat dan metode driving yang nantinya digunakan oleh kontrakor. Concrete Sheet Pile harus dipitch dan di-drive secara akurat ke posisi yang ditunjukkan gambar dan diatur pada kedalaman yang diatur Insinyur. Pile harus dipitch di dalam braced template dan diluruskan dan diatur sebelum driving. Pile harus di-drive ke penetrasi yang ditetapkan dalam cara sedemikian rupa sehingga memastikan vertikalitas pile.

Dalam proses elevasi akhir dari pile, posisi head berada di bawah permukaan tanah, dan ekskavasi (penggalian) harus dilakukan sebelum proses driving pile. Basis pondasi harus dipertimbangkan agar tidak terganggu oleh eskavasi di luar area. 


\section{Jetting}

Proses jetting pile dilakukan hanya dengan ijin Insinyur dan dalam cara yang tidak merusak kapasitas bearing dari pile yang sudah di tempatnya, tidak merusak stabilitas tanah, atau tidak merusak keamanan struktur di dekatnya. Jumlah jet dan juga volume dan tekanan air di jet nozzle harus secukupnya untuk membersihkan bahan di dekat pile. Tekanan bisa sebesar $0,5 \mathrm{~N} / \mathrm{mm} 2$ sampai 1,0 $\mathrm{N} / \mathrm{mm} 2$ tergantung pada kepadatan tanah. Pengaturan bisa dilakukan agar menjauhkan air yang muncul di permukaan tanah. Sebelum mencapai kedalaman penetrasi tidak kurang dari $1,50 \mathrm{~m}$, jet dicabut dan pile di-drive dengan hammer ke set yang ditetapkan.

\section{Proses cutoff dan splice}

Piling yang di-drive untuk pencabutan atau ke point dimana penetrasi tambahan tidak bisa tercapai, dan mengalami ekstensi di atas elevasi puncak yang melebihi toleransi, harus dipotong (cutoff) sampai elevasi yang dibutuhkan. Proses driving pile di bawah elevasi puncak adalah dilarang. Proses splice terhadap pile juga dilarang.

Puncak piling yang dipukul selama proses driving harus dipangkas bila diarahkan begitu tapi tanpa biaya ke Atasan. Hasil potongan pile menjadi properti Kontraktor dan harus dibuang dari tempat pekerjaan.

\section{Toleransi}

a) Lokasi

Pile ditempatkan berdasarkan gambar. Penempatan lateral head pile dari posisi yang ditetapkan tidak boleh melebihi $100 \mathrm{~mm}$ dalam arah mana pun.

b) Slope

Variasi dari pukulan vertikal atau yang ditetapkan tidak boleh melebihi $50 \mathrm{~mm}$.

c) Bow

Bow dari pile beton cast-in-lace tidak boleh melebihi 0,01 kekuatan pile di arah mana pun.

Toleransi Elevasi Pile Crest

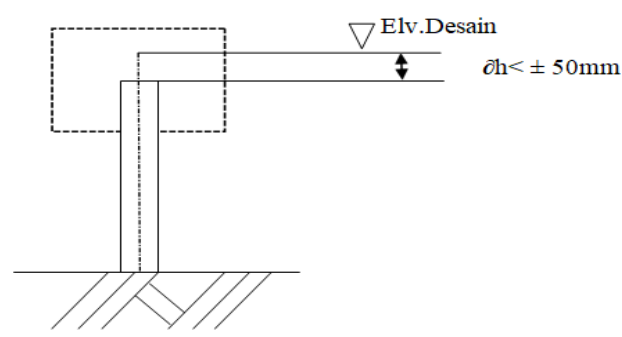

Gambar 1. Toleransi Elevasi Pile Crest

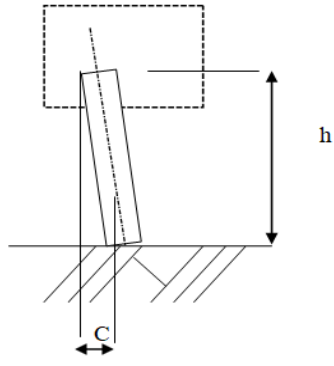

Gambar 2. Penurunan Arah Sheet Pile

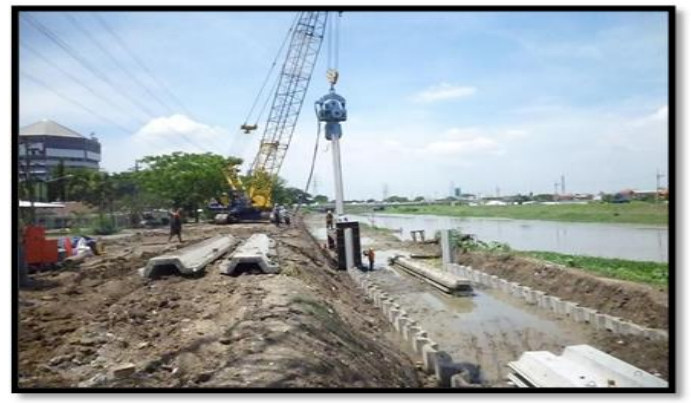

Gambar 3. Proses Driving pile CCSP dengan Vibro Hammer

\section{Coping concrete}

Beton harus di-strip sampai pada level dimana beton 32 inci memudahkan penggunaan pile cap pada $50 \mathrm{~mm}$ hingga 70 $\mathrm{mm}$. Dengan pile beton bertulang, tulang pile yang terpapar harus memiliki panjang cukup agar 32 inci berikatan penuh dengan pile cap seperti yang ditunjukkan di Gambar. Dengan pile beton pra-stress, maka kabel pra-stress terpapar harus masuk setidaknya $600 \mathrm{~mm}$ ke dalam pile cap. Ini harus didukung oleh batang tulang yang dikasting ke bagian atas pile. Alternatifnya, bonding 32 inci dibantu dengan tulang baja ringan, dan ini dikasting ke bagian atas pile selama manufaktur.

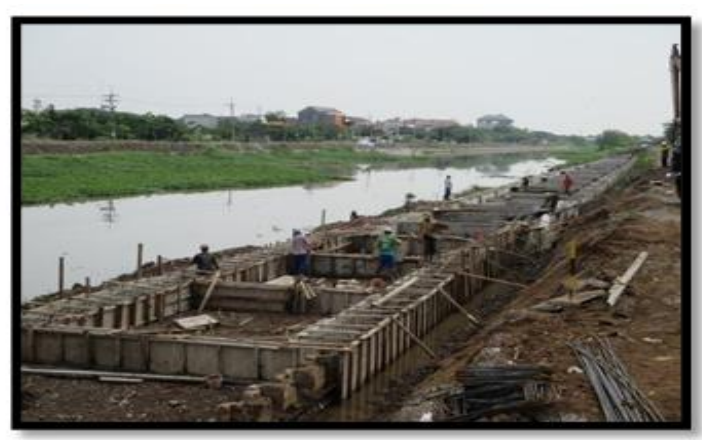

Gambar 4. Pekerjaan Bekisting Pada Coping Beam Diatas CCSP 


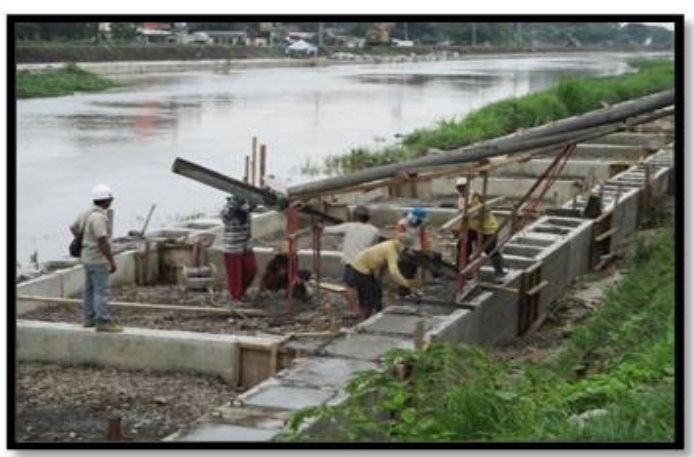

Gambar 5. Pengecoran Coping Pada CCSP

\section{Pemasangan Tie rod dan Wales}

Bila tidak ada arahan lain dari Insinyur, tie rod untuk jangkar atau dinding Sheet Pile yang didasarkan pada Gambar harus ditempatkan berdasarkan tempat backfill dan pengambilan temporary bracing. Tie Road harus dipasang sepraktis mungkin setelah penyelesaian jangkar dan wale.

Dalam proses coating, tie rod dan aksesoris yang dibutuhkan harus dilapisi oleh tar batu bara atau bahan setara, agar dilindungi dari karat. Tali harus dilapisi dengan pelumas dan poliethilen atau bahan setara, sesuai dengan Gambar agar dilindungi dari karat. Skedul yang dibuat Kontraktor atas item tersebut sudah termasuk biaya coating meski ini tidak disebut dalam item pembayaran Bill of Quantities.

\section{Backfill}

Setelah tie rod atau jangkar bumi diselesaikan, filling dilakukan ke level dan grade yang ditetapkan dalam cara yang tidak merusak tie rod atau jangkar bumi, dan juga tidak merusak wale yang sudah dipasang. Bahan filling haruslah bahan yang diseleksi oleh Insinyur sebelum pelaksanaan kerja. Semua kerja filling dilakukan berdasarkan syarat Embankment. Kompaksi (pemadatan) dilakukan oleh tenaga manusia. Pemindahan Sheet Pile harus dimonitor selama kerja backfilling. Jika pemindahan Sheet Pile harus dilakukan, kerja backfilling harus berhenti dan Kontraktor harus berdiskusi dengan Insinyur.

\section{HASIL DAN PEMBAHASAN}

Pada PLTMG Pontianak Peaker pembangunan sheet pile ini digunakan untuk menahan tanah agar tidak longsor dan meninggikan lereng suatu tanah. Sheet pile ini dibangun di daerah pinggir sungai agar tebing sungai tidak longsor.

\section{Analisis Perencanaan Sheet Pile menggunakan Software Geo5}

Analisa perhitungan daya dukung sheetpile kondisi eksisting ditinjau berdasarkan keamanan terhadap struktur, angkur, serta gaya geser (sliding) dan guling dengan kondisi normal-surut, normal-banjir, gempa-surut, gempa-banjir. Angka keamanan yang dipakai untuk kondisi normal adalah $\mathrm{SF}=2$, sedangkan untuk kondisi gempa $\mathrm{SF}=1.4$ (berdasarkan Bowles). Digunakan software Geo5 untuk menganalisa perhitungan sheetpile.

Berikut data yang digunakan dalam analisa perhitungan sheet pile:

- Data Pasang Surut:

$$
\begin{array}{ll}
\text { HHWL } & =1.14 \mathrm{~m} \\
\text { MHWL } & =0.88 \mathrm{~m} \\
\text { MSL } & =0.00 \mathrm{~m} \\
\text { MLWL } & =-0.88 \mathrm{~m} \\
\text { CDL } & =-0.89 \mathrm{~m} \\
\text { LLWL } & =-1.14 \mathrm{~m} \\
\text { LAT } & =-1.20 \mathrm{~m}
\end{array}
$$

\section{Perhitungan Daya Dukung Sheet Pile di S- 02}

Data tanah yang digunakan adalah berdasarkan data hasil sondir di lokasi pekerjaan, yaitu digunakan S.02 sebagai input software Geo5. Tiap lapisan beserta kedalaman tanah dapat dilihat sebagai berikut: 
Lapisan 1 - Very Soft Clay $(0.20-0.40)$

\begin{tabular}{|c|c|c|}
\hline \multicolumn{2}{|c|}{ Clay with low or medium plasticity $(C, C)$, soft consistency } & \multirow{8}{*}{$\begin{array}{c}- \\
- \\
- \\
- \\
-\end{array}-$} \\
\hline $\begin{array}{l}\text { Unit weight: } \\
\text { Stress:sthte: }\end{array}$ & ${ }^{\gamma}=21.00 \mathrm{bN} / \mathrm{m}^{3}$ & \\
\hline $\begin{array}{l}\text { Sungse of internal friction: } \\
\text { Ange }\end{array}$ & of $=19.00^{\circ}$ & \\
\hline Cohesion of sol : & $c_{0 f}=12.00 \mathrm{~kg}$ & \\
\hline Angle of friction struc. sol : & $5=19.00^{\circ}$ & \\
\hline $\begin{array}{l}\text { Soll: } \\
\text { Poisson's rato : }\end{array}$ & $\begin{array}{l}\text { cohesive } \\
v=0.40\end{array}$ & \\
\hline Oedometric modulus : & $E_{\text {odd }}=4.50 \mathrm{MPa}$ & \\
\hline Soturated unit weight: & $\gamma_{\operatorname{sen}}=21.00 \mathrm{kN} / \mathrm{m}^{3}$ & \\
\hline \multicolumn{3}{|c|}{ Lapisan 2 - Soft $(0.40-0.80)$} \\
\hline \multicolumn{2}{|c|}{ Sandy clay (CS), soft consistency } & \multirow{7}{*}[\begin{array}{c}{--}\\
{--}\\
{---}\end{array}]{} \\
\hline $\begin{array}{l}\text { Unit weight: } \\
\text { Stress-state : }\end{array}$ & effective $18.50 \mathrm{kV}$ & \\
\hline Angle of internal friction: & $\omega-24.50^{\circ}$ & \\
\hline $\begin{array}{l}\text { Cohesion of soll : } \\
\text { Angle of friction struc. soll : }\end{array}$ & $\begin{array}{l}c 4=14.00 \mathrm{kPO} \\
5=19.00 \%\end{array}$ & \\
\hline & cohesive 0.35 & \\
\hline $\begin{array}{l}\text { Poisson's rato : } \\
\text { Oedometric modulus : }\end{array}$ & $E_{\text {oed }}=5.00 \mathrm{MPO}$ & \\
\hline Ssturated unit weight : & $7_{\text {wat }}=18.50 \mathrm{kov} / \mathrm{m}^{3}$ & \\
\hline
\end{tabular}

Lapisan 3 - Medium $(0.80$ - 1.00)

\begin{tabular}{|c|c|c|}
\hline \multirow{2}{*}{\multicolumn{2}{|c|}{$\begin{array}{l}\text { Sandy day (CS), firm consistency } \\
\text { Unitw weght: }\end{array}$}} & \\
\hline & & --1 \\
\hline $\begin{array}{l}\text { Ande of interns firction: } \\
\text { Cohestion of sol : }\end{array}$ & $\begin{array}{l}24.500^{\circ} \\
0 \%\end{array}$ & \\
\hline 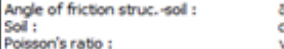 & 5 conesive $19.00^{\circ}$ & \\
\hline 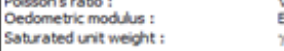 & 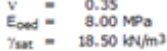 & \\
\hline
\end{tabular}

Lapisan $4-$ Stiff $(1.00-1.20)$

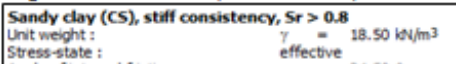

Angle of htermal friction:

Cohesion of sol:
Angle of fickon struc, -501 :

Poosson's ratio

oedometris modulus:

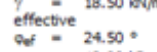

$4=18.00190$

conesive $19.00^{\circ}$

$v_{\text {end }}=0.35$

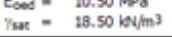

Lapisan 5 - Medium $(1.20-1.40)$

Sandy day (CS), firm consistency 1

Unit weight:

Angle of internal friction:

Cohesion of sol :

Angle of friction struc. soll :

Poisson's rata :

Dedometric modulus:
Sothrated unit weight

$1=18.50 \mathrm{kos} / \mathrm{m}^{3}$

effective $18.50 \mathrm{k}$

cof $=14.00 \mathrm{kga}$

$8=19.00^{\circ}$

cohesive 0.35

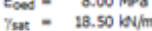

Lapisan 6 - Very Soft $(1.40-1.60)$

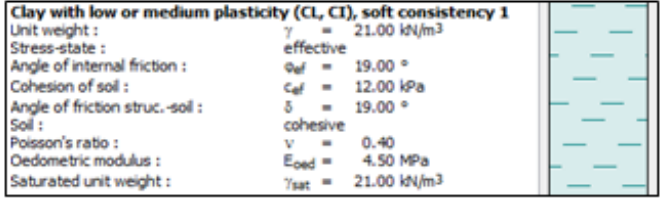

Lapisan 7 - Soft $(1.60-2.20)$

\begin{tabular}{|c|c|c|}
\hline Sandy day (CS), soft cons & & \\
\hline $\begin{array}{l}\text { Unit weight: } \\
\text { Stress-state: }\end{array}$ & ${ }_{\text {effective }}^{\gamma} 18.50 \mathrm{kN} / \mathrm{m}^{3}$ & -- \\
\hline Angle of internal friction: & $Q \alpha=24.50^{\circ}$ & - \\
\hline Cohesion of sol : & $c_{e f}=14.00 \mathrm{kPa}$ & - \\
\hline $\begin{array}{l}\text { Angle of friction struc. sol: } \\
\text { Soll: }\end{array}$ & $8=19.00^{\circ}$ & -- \\
\hline $\begin{array}{l}\text { Poisson's ratio : } \\
\text { Oedometric modius : }\end{array}$ & $v_{\text {ond }}=0.35 \mathrm{s.00} \mathrm{Mpa}$ & $-\div$ \\
\hline $\begin{array}{l}\text { Oedometric moduivs: } \\
\text { Saturated unit weight: }\end{array}$ & $\begin{array}{l}E_{\text {oed }}=5.00 \mathrm{MPa} \\
\gamma_{\text {mat }}=18.50 \mathrm{kN} / \mathrm{m}^{3}\end{array}$ & \\
\hline
\end{tabular}

Lapisan 8 - Very Soft $(2.20-3.20)$

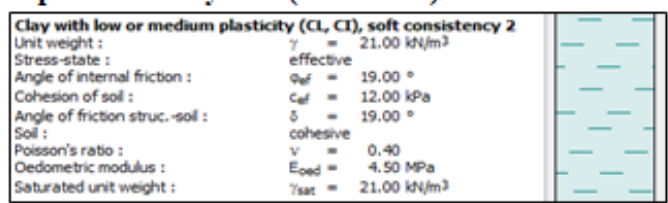

Lapisan 9 - Soft $(3.20-4.00)$

\begin{tabular}{|c|c|c|}
\hline \multicolumn{2}{|c|}{ Sandy day (CS), soft consistency 2} & \\
\hline 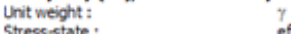 & $y=18.50 \mathrm{wN} / \mathrm{m}^{3}$ & - \\
\hline $\begin{array}{l}\text { Stress-state : } \\
\text { Angle of internal friction: }\end{array}$ & 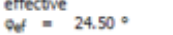 & \\
\hline Cohesion of sol: & $C_{4}=14.00 \mathrm{kPa}$ & \\
\hline $\begin{array}{l}\text { Angle of friction struc. sol : } \\
\text { Soll : }\end{array}$ & cohesive $19.00^{\circ}$ & - \\
\hline $\begin{array}{l}\text { Poisson's ratio : } \\
\text { Oedometric modulus : }\end{array}$ & $\begin{array}{l}v=0.35 \\
E_{\text {oudd }}=5.00 \mathrm{MPa}\end{array}$ & -- \\
\hline Saturated unit weight: & $=18.50{\mathrm{kN} / \mathrm{m}^{3}}^{3}$ & \\
\hline
\end{tabular}

Lapisan 10 - Very Soft $(4.00-4.20)$

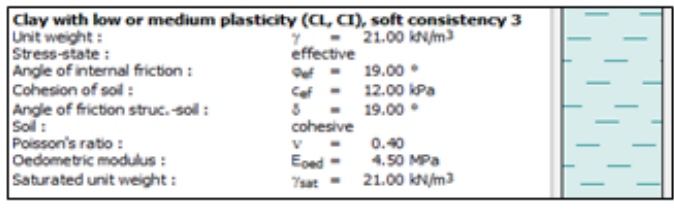

Lapisan $11-$ Soft $(4.20-8.40)$

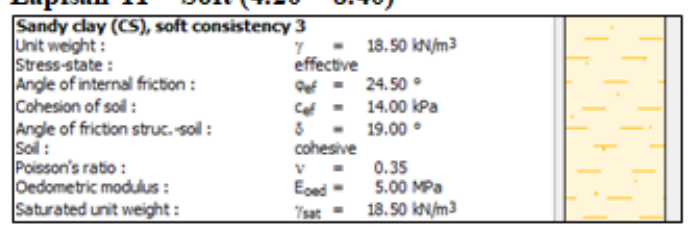

Lapisan 12 - Medium $(8.40-9.20)$

\begin{tabular}{|c|c|c|}
\hline \multicolumn{2}{|c|}{ Sandy day (CS), firm consistency 2} & \\
\hline Unit weight: & $\gamma=18.50 \mathrm{wN} / \mathrm{m}^{3}$ & -1 \\
\hline Stress-state : & effective 24.500 & $=-$ \\
\hline $\begin{array}{l}\text { Angle of internd friction: } \\
\text { Cohesion of soll: }\end{array}$ & $\begin{array}{l}\text { Se }=24.50^{\circ} \\
\text { cef }=14.00 \mathrm{~kg}\end{array}$ & $-\ldots$ \\
\hline $\begin{array}{l}\text { Angle of friction struc.-sol : } \\
\text { soll: }\end{array}$ & $s=19.00^{\circ}$ & -- \\
\hline Poisson's rabo: & $y=0.35$ & $-\quad-$ \\
\hline $\begin{array}{l}\text { Oedomettic moduius : } \\
\text { Soturated unit weight: }\end{array}$ & $\begin{array}{l}E_{\text {oed }}=8.00 \mathrm{Mpos} \\
\gamma_{\mathrm{sg}}=18.50 \mathrm{kN} / \mathrm{m}^{3}\end{array}$ & $\div-$ \\
\hline
\end{tabular}

Lapisan 13 - Soft $(9.20-10.40)$

\begin{tabular}{|c|c|c|}
\hline Sandy clay (CS), soft consistency 4 & & \\
\hline $\begin{array}{ll}\text { Unit weight: } & \gamma \\
\text { Stress-state: } & \end{array}$ & $\begin{array}{l}\gamma=18.50 \mathrm{kN} / \mathrm{m}^{3} \\
\text { effective }\end{array}$ & $-\quad-$ \\
\hline Angle of internal friction: & $\phi=24.50^{\circ}$ & - \\
\hline $\begin{array}{l}\text { Cohesion of sol : } \\
\text { Angle of friction struc. sol : }\end{array}$ & $\begin{array}{l}C \Phi^{\prime}=14.00 \mathrm{kPa} \\
5=19.00^{\circ}\end{array}$ & -- \\
\hline $\begin{array}{l}\text { Soll : } \\
\text { Possson's ratio: } \\
\text { Oedometric modulus : }\end{array}$ & $\begin{array}{l}\text { cohesive } \\
=0.35 \\
E_{\text {oed }}=5.00 \mathrm{MPa}\end{array}$ & $-\div$ \\
\hline Saturated unit weight : & $\gamma_{9:}=18.50 \mathrm{kN} / \mathrm{m}^{3}$ & \\
\hline
\end{tabular}

Saturated unit weight:

an $=18.50 \mathrm{kv} / \mathrm{m}$

\begin{tabular}{|c|c|c|}
\hline \multicolumn{2}{|c|}{ Sandy day (CS), firm consistency 3} & \multirow{2}{*}{--} \\
\hline $\begin{array}{l}\text { Unit weight: } \\
\text { Stress-state : }\end{array}$ & $\begin{array}{l}7=18.50 \mathrm{wN} / \mathrm{m}^{3} \\
\text { effective }\end{array}$ & \\
\hline Angle of internal friction: & $Q_{0}=24.50^{\circ}$ & \\
\hline Cohesion of soll : & $\varphi_{E}=14.00 \mathrm{kPa}$ & $-1-$ \\
\hline $\begin{array}{l}\text { Angle of friction struc. sol : } \\
\text { Soll: }\end{array}$ & $8=19.00^{\circ}$ & $-\ldots$ \\
\hline Poisson's ratio: & $y=0.35$ & $-\quad-$ \\
\hline Oedometric modulus : & $E_{\text {oed }}=8.00 \mathrm{Mpo}$ & \\
\hline Saturated unit weight: & $7 \mathrm{sg}=18.50 \mathrm{kN} / \mathrm{m}^{3}$ & [- \\
\hline
\end{tabular}

Saturated unit weight: $\quad r \mathrm{gs}=18.50 \mathrm{hN} / \mathrm{m}$

Lapisan 15 - Stiff (14.60 - 20.60)

\begin{tabular}{|c|c|c|}
\hline Sandy clay (CS), stiff cons & $y, S r>0.8$ & $-\sigma^{\circ}$ \\
\hline $\begin{array}{l}\text { Unit weight: } \\
\text { Stress-state : }\end{array}$ & effective $18.50 \mathrm{kN} / \mathrm{m}^{3}$ & -- \\
\hline Angle of internal friction: & $\theta_{0 .}=24.50^{\circ}$ & \\
\hline $\begin{array}{l}\text { Cohesion of sol : } \\
\text { Angle of friction struc. soll : } \\
\text { cols }\end{array}$ & $\begin{array}{l}c e d=18.00 \mathrm{kPa} \\
8=19.000^{\circ}\end{array}$ & -- \\
\hline $\begin{array}{l}\text { Soll : } \\
\text { Poisson's ratio : }\end{array}$ & $\begin{array}{l}\text { cohesive } \\
\mathrm{y}\end{array}$ & $-\div$ \\
\hline $\begin{array}{l}\text { Oedometric modulus : } \\
\text { sabrated unit weight: }\end{array}$ & $\begin{array}{l}E_{\text {oded }}=10.50 \mathrm{MPa} \\
=18.50 \mathrm{kN/m}-m^{2}\end{array}$ & \\
\hline & 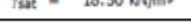 & \\
\hline
\end{tabular}

Lapisan 16 - Very Stiff $(20.60-30.00)$

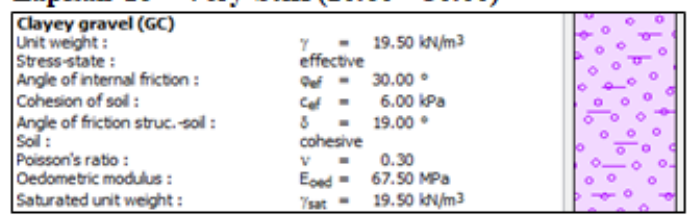

Gambar 6. Data tanah sondir di titik S-02

Gambar 6 menjelaskan tentang parameter tanah tiap-tiap lapisan tanah pada titik S-02 dan dari data tersebut digunakan sebagai input untuk mengitung stabilitas lereng dengan menggunakan bantuan Geo5. 


\subsection{Analisa Stabilitas Lereng Titik S-02}

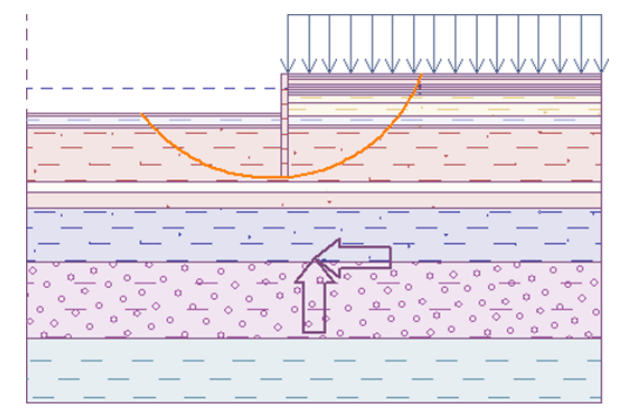

Slope stability verification (Bishop)
Sum of active forces: $F_{\mathrm{a}}=227.76 \mathrm{kN} / \mathrm{m}$

Sum of passive forces: $F_{p}=849.32 \mathrm{kN} / \mathrm{m}$

Sliding moment: $\quad \mathrm{Ma}_{\mathrm{a}}=2773.62 \mathrm{kNm}$

Resisting moment: $\quad M_{p}=10361.76 \mathrm{kNm} / \mathrm{m}$

Factor of safety $=3.73>1.40$
Slope stablity ACCEPTABIE

Gambar 7. Hasil Analisa Stabilitas Lereng kondisi Surut Gempa

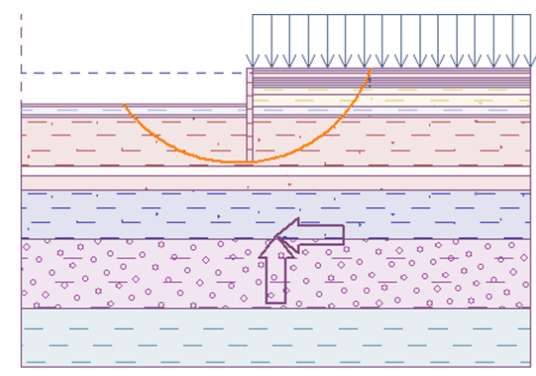

Slope stability verification (Bishop)

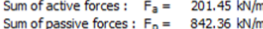

Sliding moment: $\quad \mathrm{M}_{\mathrm{z}}=2453.71 \mathrm{kNm}$

$\begin{array}{ll}\text { Siding moment: } & M_{3}=2453.71 \mathrm{kNm} / \\ \text { Resisting moment: } & M_{p}=10259.97 \mathrm{kNm} / \mathrm{m}\end{array}$

Fesctor of safety $=4.18>1.40$
Slope stablitity ACCEPTABLE

Gambar 8. Hasil Analisa Stabilitas Lereng kondisi Normal Gempa

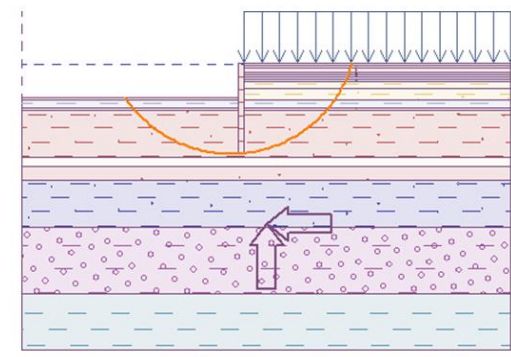

Slope stability verification (Bishop)
Sum of active forces: $F_{a}=188.81 \mathrm{kN}$

Sum of passive forces: $F_{p}=818.03 \mathrm{kN} / \mathrm{m}$

Sliding moment: $\quad M_{\mathrm{a}}=2161.90 \mathrm{kNm} / \mathrm{m}$

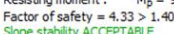

Gambar 9. Hasil Analisa Stabilitas Lereng kondisi Pasang Gempa

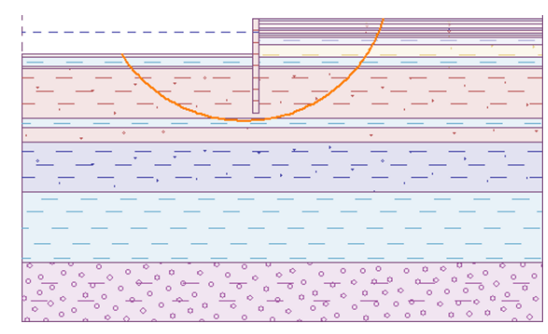

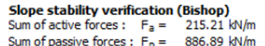

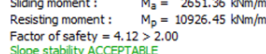

Gambar 10. Hasil Analisa Stabilitas Lereng kondisi Surut Tanpa Gempa

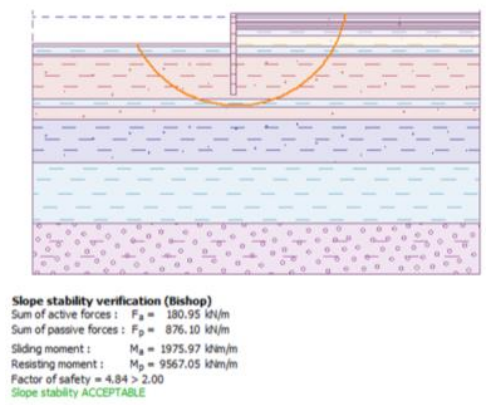

Gambar 11. Hasil Analisa Stabilitas Lereng kondisi Normal Tanpa Gempa

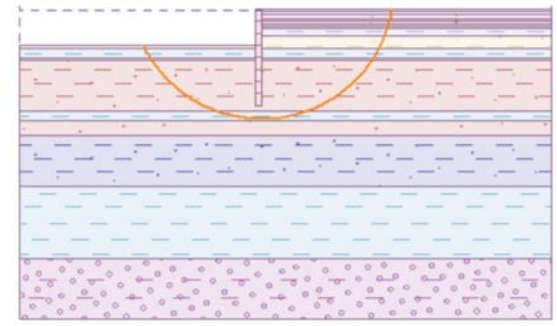

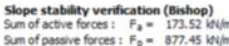

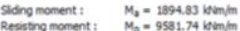

Gambar 12. Hasil Analisa Stabilitas Lereng kondisi Pasang Tanpa Gempa

Dengan analisa sheet pile di $\mathrm{S}-02$ di dapatkan rekapitulasi di setiap kondisi yaitu sebagai berikut:

Tabel 1. Rekapitulasi Hasil Analisa Sheet Pile Pada S-02.

\begin{tabular}{|l|c|c|c|}
\hline \multicolumn{1}{|c|}{ Kondisi } & $\begin{array}{c}\text { Analisa } \\
\text { Struktur }\end{array}$ & \multicolumn{2}{c|}{$\begin{array}{c}\text { Analisa Stabilitas } \\
\text { lereng }\end{array}$} \\
\hline Surut - Gempa & Aman & $3.73>1.40$ & Aman \\
\hline Normal - Gempa & Aman & $4.18>1.40$ & Aman \\
\hline Pasang - Gempa & Aman & $4.33>1.40$ & Aman \\
\hline Surut - Tanpa Gempa & Aman & $4.12>2.00$ & Aman \\
\hline Normal - tanpa Gempa & Aman & $4.80>2.00$ & Aman \\
\hline Pasang - Tanpa Gempa & Aman & $5.06>2.00$ & Aman \\
\hline
\end{tabular}

Berdasarkan hasil rekapitulasi di atas bahwa analisa sheet pile di S-02 pada kondisi 
surut-gempa, normal-gempa, pasang-gempa, surut-tanpa gempa, normal-tanpa gempa, pasang-tanpa gempa dengan gempa kala ulang 500 tahun pada analisa struktur dan analisa stabilitas lereng aman dikarenakan pada kondisi tanpa gempa nilai SF lebih besar dari 2.00 dan kondisi gempa nilai SF lebih besar dari 1.40 (Angka SF pada kondisi tanpa gempa $=2.00$ Angka SF pada kondisi gempa = 1.40).

\subsection{Perhitungan Daya Dukung Sheet Pile di S-03}

Data tanah yang digunakan adalah berdasarkan data hasil sondir di lokasi pekerjaan, yaitu digunakan S.03 sebagai input software Geo5.

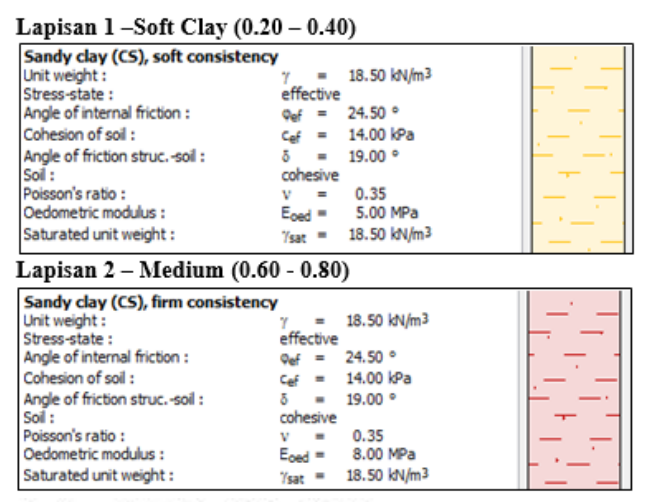

Lapisan 3 - Soft $(1.00-1.20)$

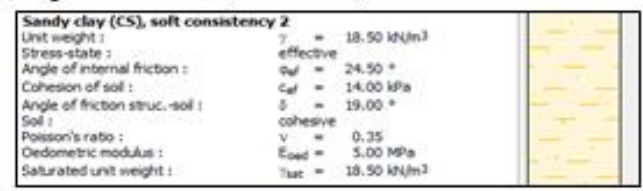

Lapisan 4 - Medium (1.20 - 1.40)

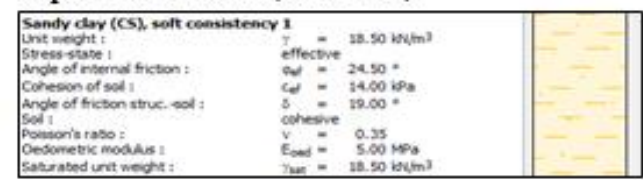

Lapisan 5 - Soft $(1.40$ - 1.60)

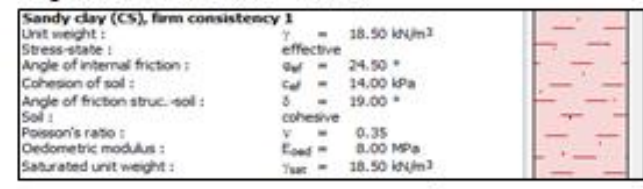

Lapisan 6 - Very Soft $(1.60-2.20)$

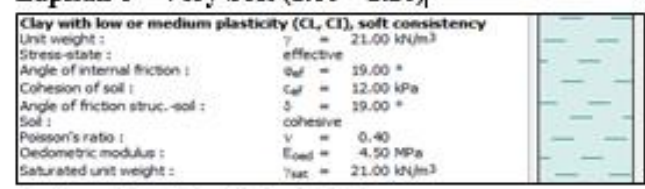

Lapisan 7 - Soft $(2.20-2.60)$

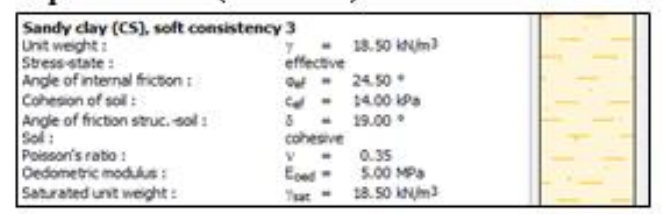

Lapisan 8 - Very Soft (2.60 - 3.40)

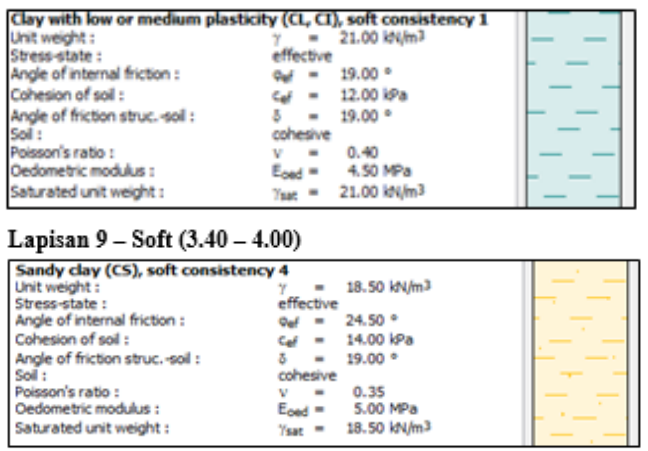

Lapisan 10 - Medium (4.00 - 4.40)

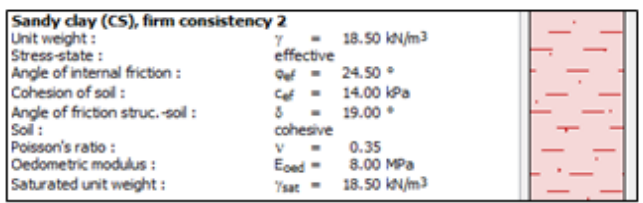

Lapisan 11 - Soft $(4.40-7.00)$

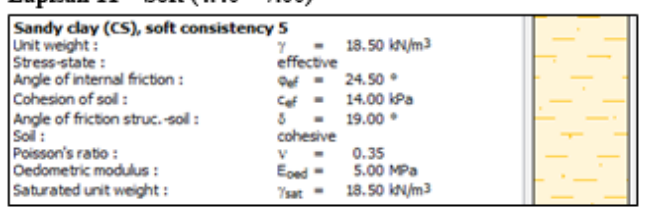

Lapisan 12 - Medium (7.00 - 13.20)

\begin{tabular}{|c|c|c|}
\hline \multicolumn{2}{|c|}{ Sandy day (CS), firm consistency 3} & \\
\hline 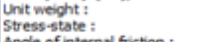 & effective ${ }^{18.50} \mathrm{bl} / \mathrm{m}^{3}$ & $E^{-}-$ \\
\hline 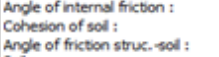 & 然 & \\
\hline 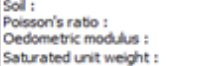 & 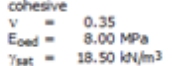 & \\
\hline
\end{tabular}

Lapisan 13 - Stiff $(13.20-21.20)$

\begin{tabular}{|c|c|c|}
\hline \multicolumn{2}{|c|}{ Sandy day (CS), stifif consistency, $\mathrm{Sr}>0.8$} & \\
\hline 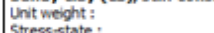 & $y=18.5$ & $-1-$ \\
\hline $\begin{array}{l}\text { Angle of interinal fiction: } \\
\text { Cohesion of sol t: }\end{array}$ & $024.500^{\circ}$ & \\
\hline $\begin{array}{l}\text { Ande of friction struc, soll : } \\
\text { sod: }\end{array}$ & $5=19.00^{\circ}$ & \\
\hline 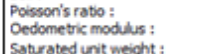 & 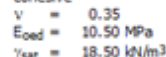 & \\
\hline & & \\
\hline
\end{tabular}

Lapisan 14 - Very Stiff (21.20 - 30.00)

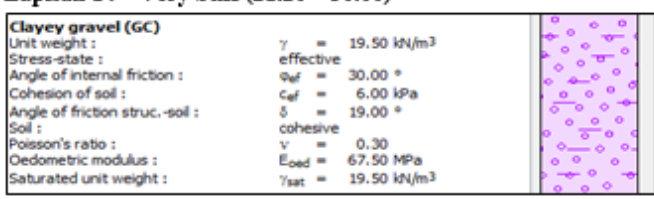

Gambar 13. Data tanah sondir di titik S-03

Gambar 13 menjelaskan tentang parameter tanah tiap-tiap lapisan tanah pada titik S-03 dan dari data tersebut digunakan sebagai input untuk mengitung stabilitas lereng dengan menggunakan bantuan Geo5. 


\subsection{Analisa Stabilitas Lereng Titik S-03}
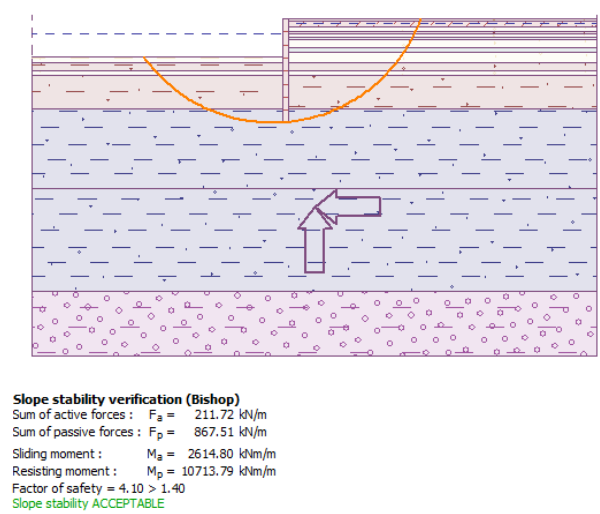

Gambar 14. Hasil Analisa Stabilitas Lereng kondisi Surut Gempa

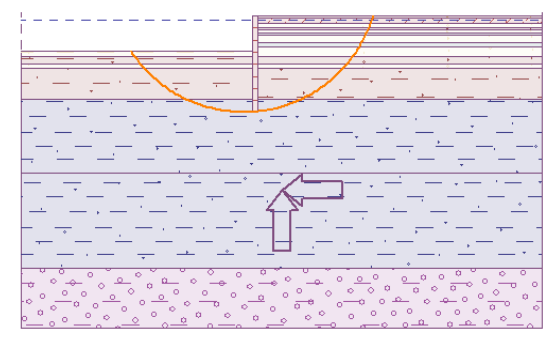

Slope stability verification (Bishop)
Sum of active forces: $F_{3}=179,13 \mathrm{kN} / \mathrm{m}$
Sum of passive forces : $F_{p}=829.17 \mathrm{kN/m}$

Sliding moment: $\quad M_{a}=2047.41 \mathrm{kNm}$

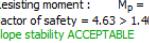

Gambar 15. Hasil Analisa Stabilitas Lereng kondisi Normal Gempa

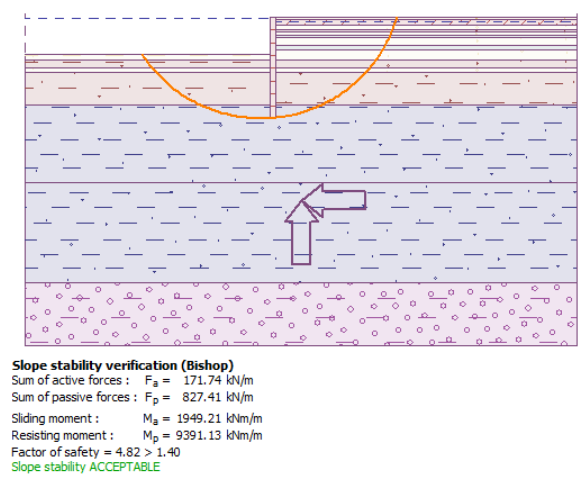

Gambar 16. Hasil Analisa Stabilitas Lereng kondisi Pasang Gempa

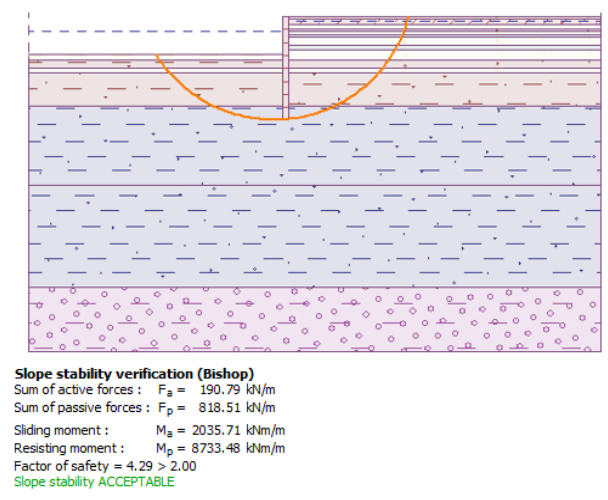

Gambar 17. Hasil Analisa Stabilitas Lereng kondisi Surut Tanpa Gempa

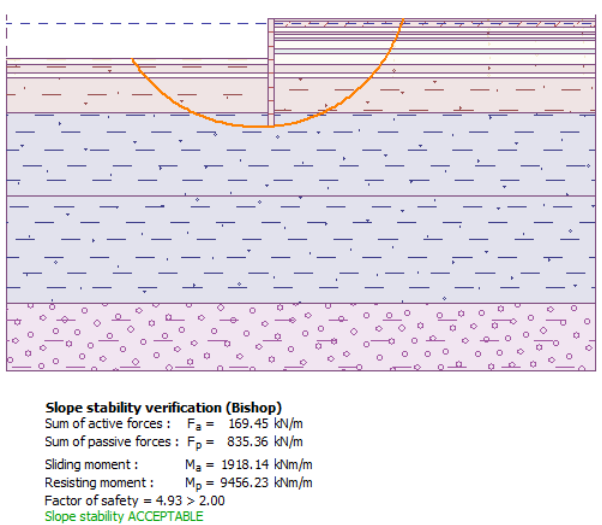

Gambar 18. Hasil Analisa Stabilitas Lereng kondisi Normal Tanpa Gempa

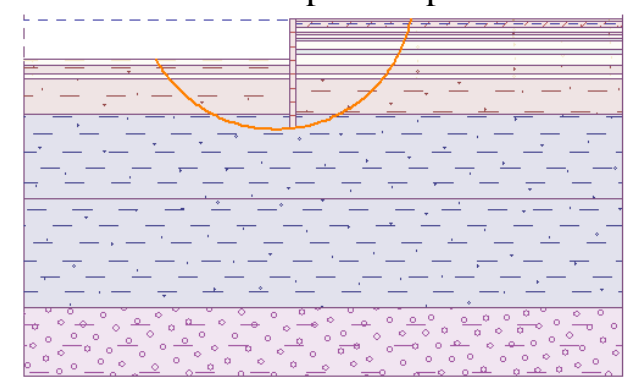

Slope stability verification (Bishop)
Sum of active forces: $F_{\mathrm{a}}=98.75 \mathrm{kN} / \mathrm{m}$

Sum of passive forces: $F_{p}=816.63 \mathrm{kN} / \mathrm{m}$

Sliding moment: $\quad M_{\mathrm{a}}=1002.32 \mathrm{kNm} / \mathrm{m}$

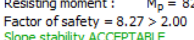

Gambar 19. Hasil Analisa Stabilitas Lereng kondisi Pasang Tanpa Gempa

Dengan analisa sheet pile di S-03 di dapatkan rekapitulasi di setiap kondisi yaitu sebagai berikut:

Tabel 2. Rekapitulasi Hasil Analisa Sheet Pile Pada S-03.

\begin{tabular}{|l|c|c|c|}
\hline \multicolumn{1}{|c|}{ Kondisi } & $\begin{array}{c}\text { Analisa } \\
\text { Struktur }\end{array}$ & \multicolumn{2}{c|}{$\begin{array}{c}\text { Analisa Stabilitas } \\
\text { lereng }\end{array}$} \\
\hline Surut - Gempa & Aman & $4.10>1.40$ & Aman \\
\hline Normal - Gempa & Aman & $4.63>1.40$ & Aman \\
\hline Pasang - Gempa & Aman & $4.82>1.40$ & Aman \\
\hline Surut - Tanpa Gempa & Aman & $4.29>2.00$ & Aman \\
\hline Normal - tanpa Gempa & Aman & $4.93>2.00$ & Aman \\
\hline Pasang - Tanpa Gempa & Aman & $8.27>2.00$ & Aman \\
\hline
\end{tabular}

Berdasarkan hasil rekapitulasi di atas bahwa analisa sheet pile di S-03 pada kondisi surut-gempa, normal-gempa, pasang-gempa, surut-tanpa gempa, normal-tanpa gempa, pasang-tanpa gempa dengan gempa kala ulang 500 tahun pada analisa struktur dan analisa stabilitas lereng aman dikarenakan pada kondisi tanpa gempa nilai SF lebih besar dari 2.00 dan kondisi gempa nilai SF lebih besar dari 1.40 (Angka SF pada kondisi tanpa gempa $=2.00$ Angka SF pada kondisi gempa = 1.40). 


\section{KESIMPULAN}

Tujuan diadakannya perencanaan sheetpile pada PLTMG Pontianak Peaker karena sheetpile menyerupai bentuk dinding vertikal tipis yang berfungsi untuk menahan tanah dan untuk menahan masuknya air ke dalam lubang galian, sebagai pondasi untuk dinding penahan tanah pada tebung jalan raya atau sungai, penahan tebing galian, bangunanbangunan di pelabuhan, dan juga sebagai pondasi.

Langkah pemasangan sheetpile proses driving sheetpile, pencabutan dan re-drive, jetting, pencatatan proses driving pile, proses cut off dan splice, toleransi, coping concrete, pemasangan tie rod dan wales, backfill, pengukuran dan pembayaran.

Pada analisis perhitungan stabilitas sheet pile yang akan di bangun di proyek PLTMG Pontianak Peaker didapatkan bahwa angka SF pada kondisi tanpa gempa (kondisi aman) = 2.00 dan angka SF pada kondisi gempa $=1.40$. Berdasarkan hasil rekapitulasi analisa sheet pile di titik S-02 dan S-03 pada kondisi-tanpa gempa, surut-tanpa gempa, banjir-tanpa gempa, normal-gempa, surut-gempa, dan banjir gempa dengan gempa di kala ulang 500 tahun pada analisa struktur dan analisa stabilitas lereng dikatakan "aman" dikarenakan pada kondisi tanpa gempa nilai SF lebih besar dari 2.00 dan kondisi gempa nilai SF lebih besar dari 1.40 .

\section{DAFTAR PUSTAKA}

Hardiyatmo, H.C., 2011. Analisis dan Perencangan Fondasi II, $2^{\text {nd }}$ ed. Yogyakarta: Gadjah Mada University Press.

Das, B.M, 2011. Principles of Foundation Engineering, Seventh edition, PWS Publishing Company.

ITB. 2005. Design of Small Dams. Oxford \& IBH Publishing CO. New Delhi Bombay Calcutta.

Kementrian Pekerjaan Umum, 1986. Buku Petunjuk Perencanaan Beton Bangunan. PU: Direktorat Jendal Pengairan.

Gunata, Rizfon. 2014. Jurnal Teknik Sipil dan Lingkungan Vol.2.No.3

Mitchell, James K. \& Villet, Willem C. B. 1987. Reinforcement of Earth Slopes and Embankments. Washington D.C: National Research Council.a.

Listyawan, Anto Budi dkk. 2013. Desain Dimensi Dinding Penahan Tanah Dengan Menggunakan Program Geo 5. Simposium Nasional RAPI XII2013FT UMS ISSN1412-9612. 